Jurnal Laut Khatulistiwa, Vol. 3. No. 2 (Juli, 2020). Hal. 55-60.

ISSN : 2614-6142 (Printed), 2614-8005 (Online)

http://jurnal.untan.ac.id/index.php/lk

JURNAL LAUT

KHATULISTIWA

\title{
Karakteristik Pasang Surut di Perairan Kuala Mempawah Kalimantan Barat
}

\section{Tidal Characteristics in the Waters of Kuala Mempawah West Kalimantan}

\author{
Jeri Solom ${ }^{*}$, Arie Antasari Kushadiwijayanto1, Yusuf Arief Nurrahman' \\ ${ }_{1}^{1}$ Laboratorium Ilmu Kelautan, FMIPA, Universitas Tanjunpura, Pontianak, Indonesia \\ *E-mail : jeri.solom@student.untan.ac.id
}

Received : 3 Juni 2020; Accepted : 24 Juni 2020

Published : 30 Juni (C) Author(s) 2020. This article is open access

\begin{abstract}
Oceanographic surveys need to be carried out to resolve the problem Lack of tidal data at Muara Mempawah. In this study, the tidal survey and analysis of tidal characteristics at the Muara Mempawah were carried out. Tidal measurements are carried out at 1-hour intervals for 30 days on measurements with three observation stations. The method used in tidal data processing in this study is the Least Squares method. Tidal types can be obtained by comparing the magnitude of the diurnal component amplitude to the semi-diurnal component. The most dominant tidal component at the estuary of the Mempawah river is K1. Based on the amplitude values of the three major harmonic components of the tide, the Formzahl number is calculated, the analysis results show that the tidal type in the study area is the dominant mixed tide on a single daily (mixed tide prevailing diurnal). With the Meso tidal category in Kuala Mempawah, the tidal range is in the range of $100 \mathrm{~cm}-200 \mathrm{~cm}$
\end{abstract}

Keywords : Tides, Least Squares, Mixed Tide Prevailing Diurnal, Meso Tidal.

\begin{abstract}
Abstrak
Survei oseanografi perlu dilakukan dalam rangka menyelesaikan masalah kurangnya data pasang surut di Muara Mempawah. Pada penelitian ini telah dilakukan survei pasang surut dan analisis terhadap karakteristik pasang surut di Muara Mempawah. Pengukuran pasang surut dilakukan dengan interval 1 jam selama 30 hari pada pengukuran dengan tiga stasiun pengamatan. Metode yang digunakan dalam pengolahan data pasang surut pada penelitian ini adalah metode Least Squares. Tipe pasang surut dapat diperoleh dengan cara membandingkan besarnya amplitudo komponen diurnal terhadap komponen semidiurnal. Komponen pasang surut yang paling dominan di Muara Sungai Mempawah adalah $\mathrm{K}_{1}$. Berdasarkan nilai amplitudo dari ketiga komponen harmonik utama pasut, dihitung bilangan Formzahl, hasil analisis menunjukan didapatkan tipe pasang surut pada daerah penelitian adalah pasang surut campuran dominan pada harian tunggal (mixed tide prevailing diurnal). Dengan demikian pasang surut di Kuala Mempawah dapat dikategori Meso tidal dengan tunggang pasang surut masing-masing kisaran $100 \mathrm{~cm}-200 \mathrm{~cm}$.
\end{abstract}

Kata kunci : Pasang surut, Least Squares, Mixed Tide Prevailing Diurnal, Meso Tidal.

\section{Pendahuluan}

Perairan Muara Mempawah merupakan salah suatu sungai yang berada di Kabupaten Mempawah. Pada daerah ini terdapat banyak aktivitas penduduk yang berfokus pada bidang kelautan seperti transportasi dan lalu lintas kapal nelayan, serta terdapat PPI (Pangkalan Pendaratan Ikan) di Pelabuhan Kuala Mempawah (Suryani, 2016). Kuala Mempawah mengalami perkembangan yang sangat pesat. Pemahaman mengenai kondisi hidro oseanografi dengan mengkaji karakteristik pasang surut di perairan ini sangat diperlukan untuk pengelolaan pelabuhan. Kurangnya data pasang surut di perairan ini berdampak pada kapal-kapal nelayan yang akan melakukan bongkar muat hasil tangkapan ikan di Pangkalan Pendaratan Ikan. 
Jurnal Laut Khatulistiwa, Vol. 3. No.2 (Juli, 2020). Hal. 55-60.

Pemahaman pasang surut sangat dibutuhkan karena pasang surut merupakan salah satu aspek penting dalam mempelajari karakteristik suatu perairan (Lindawati et al, 2018). Informasi pasang surut ini bisa digunakan untuk kegiatan navigasi dan keperluan pembangunan serta segala kegiatan yang dilakukan di perairan. Selain pasang surut dimanfaatkan untuk membantu kegiatan pelabuhan, seperti berangkat dan juga berlabuhnya kapal-kapal nelayan dari berbagai ukuran (Lisnawati et al, 2013), Pasang surut juga dapat dimanfaatkan oleh nelayan untuk mencari ikan. Ketika sedang mengalami pasang, maka ikan-ikan banyak yang ikut terbawa hingga sangat dekat dengan pesisir pantai dan Muara sungai. Oleh karena itu, perairan ini memerlukan kajian oseanografi khususnya karakteristik pasang surut agar karakteristik tersebut dapat diketahui dan dikenal oleh masyarakat di Kuala Mempawah.

Tujuan dari penelitian ini adalah memberikan gambaran mengenai karakteristik pasang surut di Perairan Kuala Mempawah Kalimantan Barat. Manfaat dari penelitian ini adalah sebagai bahan informasi baik bagi instansi pemerintah, swasta, maupun masyarakat dalam rangka mengembangkan potensi sumber daya di perairan dan dapat mengetahui karakteristik pasang surut di Perairan Kuala Mempawah Kalimantan Barat.

\section{Metode}

Penelitian ini dilakasanakan pada tanggal 3 Febuari - 4 Maret 2019, bertempat di Kuala Mempawah, Kalimantan Barat (Gambar 1.). Pengukuran lapangan dilakukan pada 3 stasiun di perairan Kuala Mempawah. Data yang diambil dalam penelitian ini berupa data elevasi muka air selama 30 hari dengan interval pengambilan data satu jam sekali. Data pasang surut pada 3 stasiun didapatkan dengan observasi langsung.

Alat dan bahan yang digunakan dalam penelitian ini berupa palm pasut dan GPS. Data pasang surut diolah menggunakan program t_tide , yang dibuat dari Pawlowicz et al., 2002 untuk mendapatkan komponen pasang surut utama. Komponen pasang surut yang dikeluarkan dari program t_tide digunakan untuk menetukan tipe pasang surut dengan mencari nilai bilangan Formzhal. Pada setiap komponen utama pasang surut pada setiap stasiun pengambilan data, serta kategori pasang surut berdasarkan tunggang pasut saat pasang purnama (spring tidal range).

$F=\frac{O_{1}+K_{1}}{M_{2}+S_{2}}$

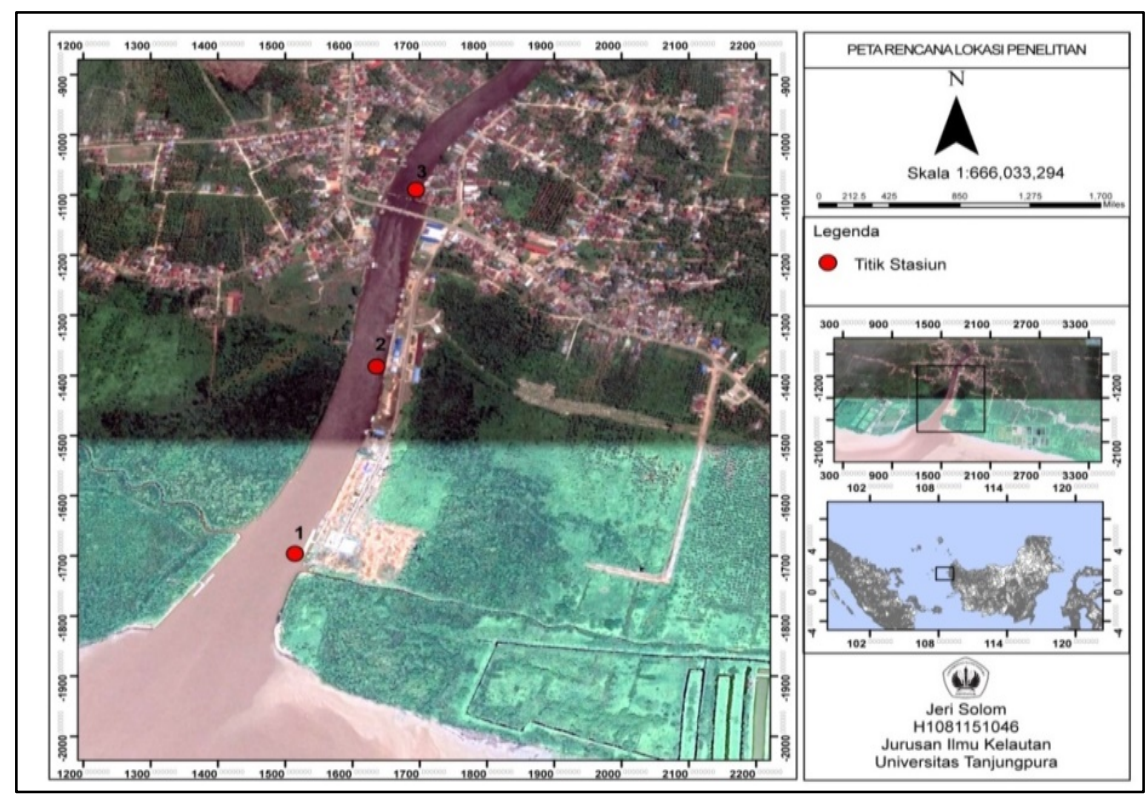

Gambar 1. Peta Lokasi Penelitian, stasiun pengamatan di titik merah 
Jurnal Laut Khatulistiwa, Vol. 3. No.2 (Juli, 2020). Hal. 55-60.

Dimana : F= bilangan Formzahl. $\mathrm{O}_{1}=$ Amplitudo komponen pasut tunggal utama yang disebabkan oleh gaya tarik bulan. $\mathrm{K}_{1}=$ amplitudo komponen pasut tunggal utama yang disebabkan oleh daya tarik bulan dan matahari. $\mathrm{M}_{2}=$ amplitudo komponen pasut ganda utama yang disebabkan oleh gaya tarik bulan. $S_{2}=$ amplitudo komponen pasut ganda utama yang disebabkan oleh gaya tarik matahari.

\section{Hasil dan Pembahasan}

\subsection{Hasil Pengukuran dan Analisis Harmonik Pasang Surut}

Hasil pengamatan pada ketiga stasiun secara umum hampir sama tetapi jika di lihat lebih lanjut stasiun satu lebih besar dari stasiun dua dan stasiun tiga. Untuk stasiun satu ditunjukkan dengan grafik berwarna biru sedangkan untuk stasiun dua berwarna merah dan untuk stasiun tiga berwarna hijau dapat dilihat pada Gambar 2. Dari hasil pengamatan ketiga stasiun didapatkan fase pasang purnama sebanyak 2 kali pasang purnama dan untuk fase pasang perbani juga didapatkan 2 kali pasang perbani.

Hasil analisa menunjukkan pasang surut di perairan Muara Mempawah dipengaruhi oleh perubahan deklinasi bulan dan matahari. Komponen pasang surut yang paling dominan di muara sungai Mempawah adalah $K_{1}$. Dominan $\mathrm{K}_{1}$ ini ditunjukan dengan nilai amplitudo paling tinggi dari antara yang lainnya, sedangkan sebaliknya, komponen yang paling kecil pengaruhnya adalah $S_{2}$ dapat dilihat juga pada Tabel 1.

Berdasarkan data pengukuran pasang surut dilapangan menunjukkan pasang surut tertinggi pada stasiun 1 , stasiun 2 dan stasiun 3 terjadi pada tanggal 20 Febuari 2019 yaitu sebesar $159 \mathrm{~cm}$ (gambar 3). Hal ini terjadi karena pada waktu tersebut posisi bulan bumi dan matahari berada pada satu garis lurus sehingga menyebabkan pasang tertinggi pada waktu tersebut, selain itu variasi pasang surut juga disebabkan karena faktor topografi yang bervariasi. Dari hasil perhitungan MSL (menggunakan rumus MSL) diperoleh nilai MSL pasut di Stasiun 1 sebesar $63.6 \mathrm{~cm}$, Stasiun 2 sebesar $76.4 \mathrm{~cm}$ dan Stasiun 3 sebesar 94.6 $\mathrm{cm}$.

Dari hasil pengolahan data pasang surut didapatkan hasil bahwa nilai pasutnya mempunyai tipe pasut campuran condong ke harian tunggal (mixed tide prevailing diurnal) pada tipe ini dalam satu hari terjadi satu kali pasang dan satu kali air surut, tetapi kadangkadang untuk sementara waktu terjadi dua kali pasang dan dua kali surut dengan periode yang sangat berbeda. dengan nilai rentang bilangan formzahl antara 1,5 sampai 3,0. Dari hasil ini dapat dianalisa bahwa suatu perairan selalu mempunyai tipe pasut yang sama namun angka dari tipe pasut/bilangan formzahl nya yang selalu berubah-ubah setiap rentang waktu tertentu (Qhomariyah dan Yuwono, 2016).

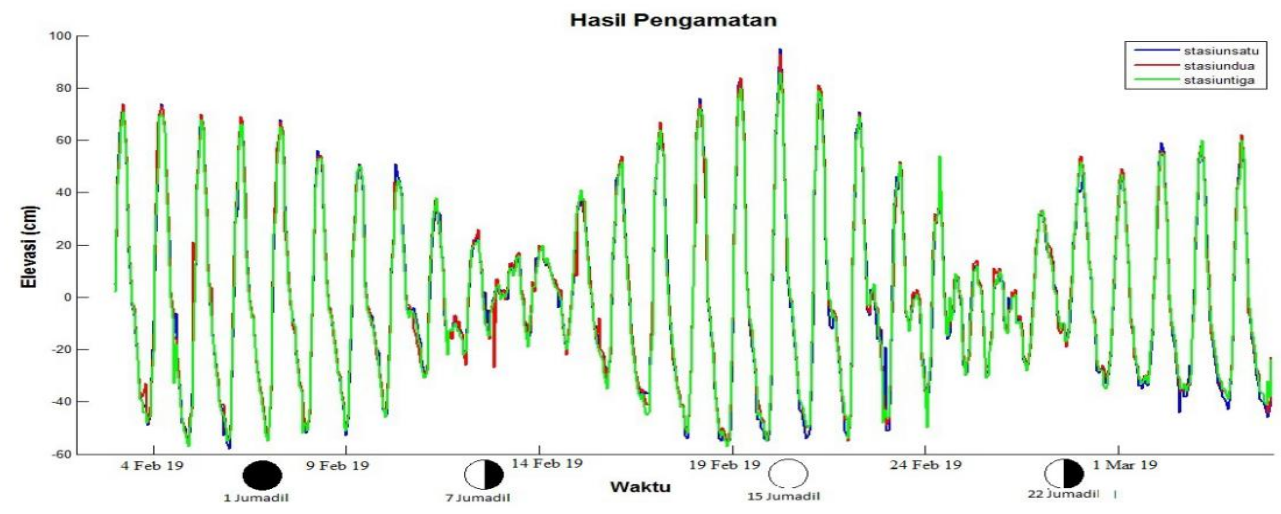

Gambar 2. Data Pengamatan Stasiu 1, Stasiun 2 dan Stasiun 3. 
Jurnal Laut Khatulistiwa, Vol. 3. No.2 (Juli, 2020). Hal. 55-60.
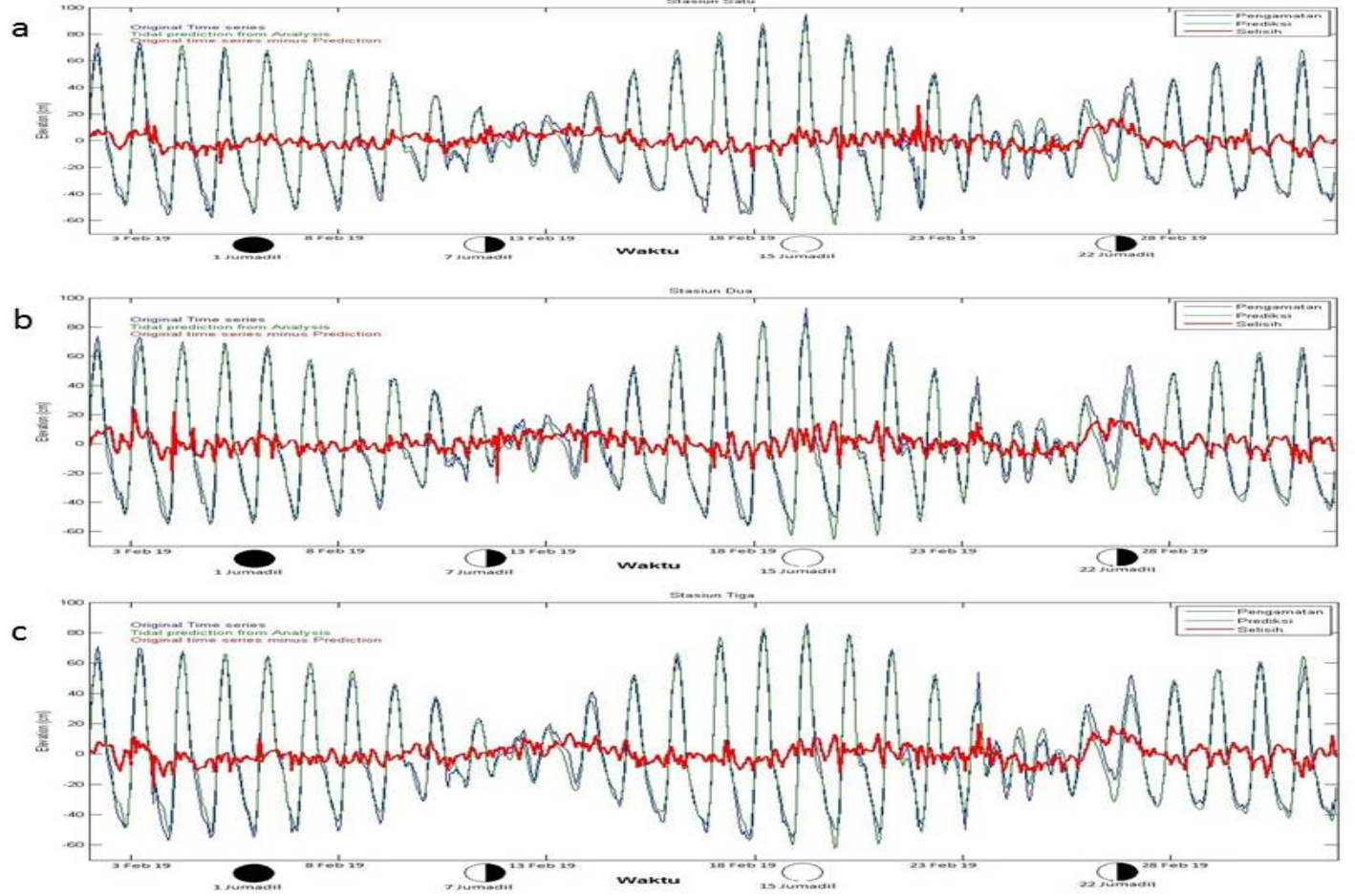

Gambar 3. Data Pengamatan, Prediksi dan Rasio pasang surut di stasiun satu (a), dua (b) dan tiga (c)

Amlitudo komponen pasang surut utama dari mulut Muara sungai sampai ke Sungai Mempawah menunjukan bahwa setiap Komponen utama pasang surut mengalami penurunan dari stasiun satu ke stasiun tiga. Dimana nilai amplitudo yang terendah yaitu komponen $\mathrm{S}_{2}$, sedangkan kebalikannya komponen amlitudo tertinggi yaitu komponen $\mathrm{K}_{1}$ pada setiap stasiun.

\subsection{Pola Pasang Surut}

Tipe pasang surut dapat diperoleh dengan cara membandingkan besarnya amplitudo komponen diurnal terhadap komponen semidiurnal (Lindawati et al, 2018). Besarnya bilangan Formzahl di Muara sungai mempawah, pada setiap stasiun satu, dua dan tiga secara berturut adalah 2,62, 2,62 dan 2,68. Hal ini menandakan tipe pasang surut pada daerah penelitian adalah pasang surut campuran dominan pada harian tunggal. Hasil nilai Formzahl diperkuat oleh (Prasetyo, 2016) bahwa untuk nilai $1,5<\mathrm{F}<3$ maka tipe pasut sebagai campuran dominan pada harian tunggal (mixed tide prevailing diurnal). Nilai bilangan Formzahl terendah diperoleh pada stasiun satu, sebaliknya nilai bilangan fromzahl yang tertinggi pada pada stasiun tiga.

Tipe pasang surut berdasarkan tunggang pasut saat pasang purnama pada muara sungai Mempawah dapat dikategorikan meso tidal (kisaran $100 \mathrm{~cm}-200 \mathrm{~cm}$ ) pada ketiga stasiun pengamatan, Tabel 2. (Pamungkas, 2018) menjelaskan bahwa range pasang-surut dapat dikategorikan Mikro-tidal (kisaran $0.3-1 \mathrm{~m}$ ), Meso tidal (kisaran 1 - 2m), dan Makro tidal (kisaran > 3m).

Berdasarkan data yang diperoleh dari hasil pengukuran pasang surut selama 30 hari. Dilakukan perhitungan dengan menggunakan nilai-nilai komponen harmonik tersebut maka didapatkan nilai Tinggi Muka Air Rata-rata (Mean Sea Level), Air Rendah Terendah (Lowest Low Water Level), Air Tinggi Tertinggi (Highest High Water Level), Muka air tinggi rerata (mean high water level), Muka air rendah rerata (mean low water level), Chart Datum Level, Muka Surutan (Zo), dan Rendah pasang surut (Lowest Astronomical Tide) dapat dilihat pada Tabel 2 . 
Jurnal Laut Khatulistiwa, Vol. 3. No.2 (Juli, 2020). Hal. 55-60.

Tabel 1. Amplitudo dan Fase Komponen Harmonik di masing-masing Stasiun

\begin{tabular}{clcccc}
\hline Stasiun & Besaran & $\mathrm{K}_{1}$ & $\mathrm{O}_{1}$ & $\mathrm{M}_{2}$ & $\mathrm{~S}_{2}$ \\
\hline \multirow{2}{*}{1} & Amplitudo $(\mathrm{cm})$ & 33.1534 & 28.3020 & 15.0763 & 8.3513 \\
& Fase $(\mathrm{o})$ & 138.20 & 45.81 & 125.35 & 166.67 \\
2 & Amplitudo $(\mathrm{cm})$ & 32.9555 & 27.5826 & 14.9119 & 8.1493 \\
& Fase $(\mathrm{o})$ & 137.80 & 45.32 & 123.83 & 163.70 \\
3 & Amplitudo $(\mathrm{cm})$ & 32.9144 & 27.7706 & 14.7361 & 7.8853 \\
& Fase $(\mathrm{o})$ & 137.78 & 46.12 & 123.40 & 165.38 \\
\hline
\end{tabular}

Tabel 2. Kedudukan muka air di Stasiun Pengamatan pasut

\begin{tabular}{cccc}
\hline Kedudukan muka Air & $\begin{array}{c}\text { Stasiun } 1 \\
(\mathrm{~cm})\end{array}$ & $\begin{array}{c}\text { Stasiun } 2 \\
(\mathrm{~cm})\end{array}$ & $\begin{array}{c}\text { Stasiun } 3 \\
(\mathrm{~cm})\end{array}$ \\
\hline HHWL & 148,4830 & 159,9993 & 177,9064 \\
Z0 & 146,3384 & 144,1374 & 143,9914 \\
MHWL & 140,1317 & 151,85 & 170,0211 \\
MLWL & 40,1724 & 53,3388 & 71,9786 \\
LLWL & 2,1446 & 15,8619 & 33,915 \\
CDL & $-21,283$ & $-7,1993$ & 11,2936 \\
LAT & 26,9467 & 40,6681 & 58,9441 \\
\hline
\end{tabular}

Peredaman pasang surut pada stasiun satu, dua dan stasiun tiga dimana fase komponen $\mathrm{K}_{1}$ dari stasiun dua menuju ke stasiun tiga terjadi peredamana yang paling kecil dari komponen utama pasut, sedangkan peredaman paling besar yaitu fase komponen $S_{2}$ yang terjadi dari stasiun dua menuju ke stasiun tiga. Komponen pasang surut dari stasiun satu ke stasiun dua diketahui peredamana pasang surut di dominansi oleh fase komponen diurnal $\mathrm{O}_{1}$ dan untuk stasiun dua ke stasiun tiga peredamana pasang surut di dominan oleh fase komponen semi diurnal $\mathrm{S}_{2}$.

\section{Kesimpulan}

Berdasarkan hasil penelitian dan pembahasan pada bab-bab sebelumnya dapat diambil kesimpulan berupa gambaran mengenai karakteristik pasang surut di Perairan Kuala Mempawah Kalimantan Barat di ketahui dari nilai konstanta harmonik pasang surut air laut berdasarkan bilangan fromzahl, didapatkan hasil analisa jenis pasang surut pada perairan muara Mempawah adalah pasang surut campuran dominan pada harian tunggal.

Tipe pasang surut berdasarkan tunggang pasut saat pasang purnama pada muara sungai Mempawah dapat dikategorikan meso tidal (kisaran $100 \mathrm{~cm}-200 \mathrm{~cm}$ ) pada ketiga stasiun pengamatan.

\section{Daftar Pustaka}

Lindawati, M.I. Jumarang, A.A. Kushadiwijayanto. 2018. Karakteristik Perambatan Gelombang Pasang Surut di Estuari Kapuas Kecil. Jurnal Laut Khatulistiwa. 1(3):61-66

Lisnawati, L.A, B. Rochaddi, D.H. Smunarti. 2013. Studi Tipe Pasang Surut di Pulau Parang Kepulauan Karimunjawa Jepara Jawa Tengah. Jurnal Oseanografi. 2(3):214220

Pamungkas, A. 2018. Karakteristik Parameter Oseanografi (Pasang-Surut, Arus, dan Gelombang) di Perairan Utara dan Selatan Pulau Bangka. Buletin Oseanografi Marina. 7(1):51-58.

Prasetyo, D., V. Dermawan, dan H.A. Primantyo. 2016. Kajian penanganan. Sedimentasi sungai banjir kanal barat kota semarang (study of sedimentation mitigation west floodway semarang city). Jurnal Teknik Pengairan. 6(1):76-87. 
Jurnal Laut Khatulistiwa, Vol. 3. No.2 (Juli, 2020). Hal. 55-60.

Qhomariyah, Lailatul dan Yuwono., 2016, Analisa Hubungan antara Pasang Surut Air Laut dengan Sedimentasi yang Terbentuk (Studi Kasus : Dermaga Pelabuhan Petikemas Surabaya). Jurnal TEKNIK ITS. 5(1): 2337-3539.

Suryani, D., M.I. Jumarang, dan Apriansyah. 2016. Perbandingan Kecepatan Arus Pasang Surut Dibeberapa Lokasi di Pantai Barat Kalimantan Barat. Jurnal Prisma Fisika. 4(2): 45-49.

Umami, R.M., Hariyadi, dan R. Baskoro. 2014. Sebaran Konsentrasi Sedimen Tersuspensi di Perairan Larangan, Kabupaten Tegal Menggunakan Model Matematik 2 Dimensi Sed2d. Jurnal Oseanografi. 3(2): 124-134. 